Care: Jurnal Ilmiah Ilmu Kesehatan Vol .7, No.3, 2019, hal 149-157

Tersedia online di https://jurnal.unitri.ac.id/index.php/care

ISSN 2527-8487 (online)

ISSN 2089-4503 (cetak)

\title{
HUBUNGAN BUDAYA ORGANISASI TERHADAP MUTU ASUHAN KEPERAWATAN
}

\author{
Abdul Muhith", Rachma Rizqina ${ }^{2)}$, Diah Zulailah ${ }^{3)}$ \\ ${ }^{1)}$ Dosen Fakultas Keperawatan dan Kebidanan Universitas Nahdlatul Ulama Surabaya \\ ${ }^{2)}$ Dosen Manajemen Universitas Nahdlatul Ulama Surabaya \\ ${ }^{3)}$ Keperawatan Stikes Majapahit Mojokerto \\ E-mail : abdulmuhith@unusa.ac.id
}

\begin{abstract}
Hospitals as health care institutions need to improve their skills, speed, ease and accuracy in performing nursing practice. The right organizational culture can easily direct and focus on improving the quality of nursing care. The purpose of this study to analyze the relationship of organizational culture with the quality of nursing care in RSI Sawatah Mojokerto Inpatient Room. This research used cross sectional approach. The population in this study were all nurses in RSI Sawatah Mojokerto Inpatient Room with the number of samples of 85 nurses with total sample technique. Measurers in this study used OCAI for Organizational culture and quality questionnaire of nursing care. Statistical analysis used was Spearman Rank test.The result of analysis was found that almost half of the nurses in SSI inpatient unit of RSI Sakinah Mojokerto embraced Hierarchy Organization Culture as many as 29 respondents (34.1\%) and for Good Nursing Standards were 66 respondents (77.6\%) while High Professional Performance Standards, was as many as 66 respondents $(77.6 \%)$. Spearman test analysis results obtained significance value $(p)=0.018$ which explains that there was Organizational Culture Relation with Nursing Care Quality in Inpatient Room RSI Sakinah Mojokerto. Hospitals as a place of health services should be able to develop appropriate organizational culture and improve the quality of nursing care through training, research, supervision, and other methods that are effective and efficient.
\end{abstract}

Keywords: Nursing Care; Organizational Culture; Quality; Nurse.

\begin{abstract}
ABSTRAK
Rumah sakit sebagai institusi pelayanan kesehatan perlu meningkatkan keterampilan, kecepatan, kemudahan dan ketepatan dalam melakukan tindakan praktek keperawatan. Budaya organisasi yang tepat dapat dengan mudah mengarahkan dan memfokuskan dalam meningkatkan mutu asuhan keperawatan. Tujuan penelitian ini untuk menganalisis hubungan budaya organisasi dengan mutu asuhan keperawatan di Ruang Rawat Inap RSI Sakinah Mojokerto. Penelitian ini menggunakan pendekatan cross sectional. Populasi dalam penelitian ini semua perawat di Ruang Rawat Inap RSI Sakinah Mojokerto dengan jumlah sampel penelitian
\end{abstract}

Cara mengutip: Muhith, Abdul., Rizqina, Rachma., \& Zulailah, Diah. (2019). Hubungan Budaya Organisasi Terhadap Mutu Asuhan Keperawatan. Care:Jurnal Ilmiab Ilmu Kesehatan, 7(3), 149-157 
85 perawat pelaksana dengan teknik total sampel. Alat ukur pada penelitian ini menggunakan menggunakan OCAI untuk budaya Organisasi dan kuesioner mutu asuhan keperawatan. Analisa statistik yang digunakan adalah uji Spearman Rank. Hasil analisis didapat hampir setengahnya perawat yang bertugas di ruang rawat Inap RSI Sakinah Mojokerto menganut Budaya Organisasi Hierarki sebanyak 29 responden (34,1\%) dan untuk Standar Asuhan Keperawatan Baik sebanyak 66 responden $(77,6 \%$ ) sedangkan Standar Kinerja Profesional Tinggi, yaitu sebanyak 66 responden $(77,6 \%)$. Hasil analisa uji Spearman diperoleh nilai signifikansi $(p)=0,018$ yang menjelaskan bahwa ada Hubungan Budaya Organisasi dengan Mutu Asuhan Keperawatan di Ruang Rawat Inap RSI Sakinah Mojokerto. Rumah Sakit sebagai tempat pelayanan kesehatan hendaknya dapat mengembangkan budaya organisasi yang tepat dan meningkatkan mutu asuhan keperawatan melalui pelatihan, penelitian, supervisi, dan metode lain yang efektif serta efisien.

Kata Kunci : Asuhan Keperawatan; Budaya Organisasi; Mutu; Perawat.

\section{PENDAHULUAN}

Organisasi pelayanan kesehatan, seperti rumah sakit perlu memiliki karakter mutu pelayanan prima yang sesuai dengan harapan pasien. Semakin baik penilaian pasien, maka semakin baik pula mutu pelayanan kesehatan rumah sakit tersebut. Mutu pelayanan rumah sakit dapat dinilai dari tiga komponen sistem manajemen, yaitu: 1) Struktur, 2) Proses, 3) Outcome, (Muhith, 2017). Supaya dapat mewujudkan mutu layanan yang baik dan layak, tentunya dengan dilakukannya pembenahanpembenahan mulai dari faktor internal yaitu manajemen pengelolaan tugas-tugas dan sumber daya manusia serta menjunjung tinggi budaya organisasi yang merupakan ujungtombak dari pelayanan kesehatan terhadap masyarakat dalam mewujudkan pelayanan kesehatan yang baik. Pelayanan asuhan keperawatan sebagai bagian integral pelayanan kesehatan mempunyai kontribusi yang sangat besar dalam menentukan kualitas pelayanan di rumah sakit. Sehingga setiap upaya untuk meningkatkan kualitas pelayanan rumah sakit harus juga disertai upaya untuk meningkatkan kualitas pelayanan keperawatan. Mutu kualitas pelayanan dipengaruhi faktor budaya organisasi (Winasih dkk, 2015).

Hasil studi pendahuluan yang dilakukan peneliti pada tangal 16 Januari 2016 di RSI

Sakinah Mojokerto didapatkan data pada tahun 2017 jumlah tempat tidur sebanyak 215, jumlah pasien MRS sebanyak 14.472, jumlah pasien KRS sebanyak 14.4042 (pasien keluar meninggal $<48$ jam sejumlah 314 yaitu $0,21 \%$ dan meninggal $>48$ jam sejumlah 364 yaitu 0,25\%, data tersebut dapat diketahui dari jumlah BOR 77,93\%, ALOS 4,6 hari, TOI 1,1 hari dan BTO 70,1 kali. Kepuasan pasien sebesar 98\% pada penilaian kecepatan (Responsive) dan ketepatan pelayanan, keramahan 
(Empathy) petugas, kejelasan informasi yang disampaikan oleh perawat.

Berdasarkan uraian latar belakang tersebut rumah sakit sebagai institusi pelayanan kesehatan adalah meningkatkan keterampilan, kecepatan, kemudahan dan ketepatan dalam melakukan tindakan praktek keperawatan pelayanan kesehatan serta lebih bertanggung jawab dalam memberikan pelayanan dan dengan adanya budaya organisasi akan menjadi lebih mudah untuk mengarahkan dan memfokuskan dalam meningkatkan mutu asuhan keperawatan. Sehingga penulis ingin melakukan penelitian mengenai Hubungan Budaya Organisasi dengan Mutu Asuhan Keperawatan Di Ruang Rawat Inap RSI Sakinah Mojokerto.

\section{METODE PENELITIAN}

Penelitian ini menggunakan desain Analitik Korelasi dengan pendekatan cross sectional. Populasi dalam penelitian ini semua perawat di Ruang Rawat Inap RSI Sakinah Mojokerto dengan jumlah sampel penelitian 85 perawat dengan teknik total sampel. Instrumen penelitian ini menggunakan kuisioner OCAI untuk budaya Organisasi dan kuesioner Mutu Asuhan Keperawatan. Data yang diperoleh akan diolah dengan melakukan analisis menggunakan uji statistik uji Spearman Rank dengan signifikan $\alpha<0,05$.

\section{HASIL}

Penelitian dilakukaan di seluruh Ruang Rawat Inap RSI Sakinah Mojokerto Jl. R.A. Basuki No. 12, Sookoo Mojokerto, Jawa Timur 61361 pada bulan Februari - Maret tahun 2018.

Tabel 1. Tabulasi silang Hubungan BudayaOrganisasi dengan Mutu Asuhan Keperawatan (Standar Asuhan Keperawatan) di Ruang Rawat Inap RSI Sakinah Mojokerto.

\begin{tabular}{|c|c|c|c|c|c|c|}
\hline \multirow[t]{3}{*}{ Budaya Organisasi } & \multicolumn{4}{|c|}{ Standar Asuhan Keperawatan } & \multicolumn{2}{|c|}{ Total } \\
\hline & \multicolumn{2}{|c|}{ Cukup } & \multicolumn{2}{|c|}{ Baik } & & \\
\hline & $f$ & $\%$ & f & $\%$ & $f$ & $\%$ \\
\hline Clan & 7 & 8,2 & 17 & 20,0 & 24 & 28,2 \\
\hline Adokrasi & 8 & 9,4 & 1 & 1,2 & 9 & 10,6 \\
\hline Market & 0 & 0,0 & 23 & 27,1 & 23 & 27,1 \\
\hline Hierarki & 4 & 4,7 & 25 & 29,4 & 29 & 34,1 \\
\hline Total & 19 & 22,4 & 66 & 77,6 & 85 & 100 \\
\hline
\end{tabular}

Berdasarkan Tabel 1 menunjukkan bahwa hampir setengahnya Budaya Organisasi yang dianut adalah Hierarki dengan Standar Asuhan Keperawatan Baik sebanyak 25 responden (29,4\%). Melalui hasil statistik uji Spearman pada taraf sig $(0,05)$ diperoleh hasil korelasi bahwa nilai korelasi $0,018 \quad(<0,05)$ artinya ada 
hubungan Budaya Organisasi dengan

Standar Asuhan Keperawatan di Ruang

Rawat Inap RSI Sakinah Mojokerto.

Berdasarkan Tabel 2 menunjukkan bahwa hampir setengahnya Budaya Organisasi yang dianut adalah Hierarki dengan Standar Kinerja Profesional Perawat Tinggi sebanyak 25 responden (29,4\%). Melalui hasil statistik uji Spearman pada taraf sig $(0,05)$ diperoleh hasil korelasi bahwa nilai korelasi $0,018 \quad(<0,05)$ artinya ada hubungan Budaya Organisasi dengan Standar Asuhan Keperawatan di Ruang Rawat Inap RSI Sakinah Mojokerto.

Tabel 2. Tabulasi silang Hubungan Budaya Organisasi dengan Mutu Asuhan Keperawatan (Standar Kinerja Profesional Perawat) di Ruang Rawat Inap RSI Sakinah Mojokerto.

\begin{tabular}{|c|c|c|c|c|c|c|}
\hline \multirow[t]{3}{*}{ Budaya Organisasi } & \multicolumn{4}{|c|}{ Standar Asuhan Keperawatan } & \multicolumn{2}{|c|}{ Total } \\
\hline & \multicolumn{2}{|c|}{ Cukup } & \multicolumn{2}{|c|}{ Baik } & & \\
\hline & $f$ & $\%$ & $f$ & $\%$ & $f$ & $\%$ \\
\hline Clan & 7 & 8,2 & 17 & 20,0 & 24 & 28,2 \\
\hline Adokrasi & 8 & 9,4 & 1 & 1,2 & 9 & 10,6 \\
\hline Market & 0 & 0,0 & 23 & 27,1 & 23 & 27,1 \\
\hline Hierarki & 4 & 4,7 & 25 & 29,4 & 29 & 34,1 \\
\hline Total & 19 & 22,4 & 66 & 77,6 & 85 & 100 \\
\hline
\end{tabular}

\section{PEMBAHASAN}

Budaya Organisasi di Ruang Rawat Inap RSI

\section{Sakinah Mojokerto}

Hasil penelitian menunjukkan bahwa dari 85 responden hampir setengahnya menganut Budaya Organisasi Hierarki sebanyak 29 responden (34,1\%). Budaya organisasi didefinisikan sebagai gejala dinamis di sekeliling kita sepanjang waktu yang secara terus menerus dilakukan dan diciptakan melalui interaksi dengan pihak lain dan dibentuk oleh perilaku pimpinan dan yang terdiri dari struktur, rutinitas, aturan-aturan, dan norma norma yang membimbing dan membatasi perilaku (Iranita 2013).Kesuksesan organisasi banyak dipengaruhi oleh berbagai faktor dimana salah satunya adalah faktor budaya organisasi yang berfungsi sebagai kekuatan, penggerak dalam pencapaian tujuan, dan pembeda antara organisasi yang satu dengan yang lainnya. Apabila sebuah organisasi memiliki anggota atau perawat yang masih aktif, maka dapat diindikasikan sebagai bukti bahwa organisasi tersebut telah mampu dan sukses dalam memfungsikan budaya organisasi sebagai perekat di dalam kegiatan organisasi setiap harinya serta sebagai pengikat kekompakan antara perawat dalam organisasi (Andisiri dkk, 2017). 
Budaya Organisasi yang dominan di Ruang Rawat Inap RSI Sakinah Mojokerto adalah Budaya Hierarki dimana jenis budaya organisasi ini dicirikan oleh suatu formalisasi dan prosedur kerja yang terstruktur hal ini dibuktikan dari hasil penelitian yang di dapatkan melalui kuesiner OCAI yaitu Tim perawat sudah sangat terkontrol dan sudah terstruktur jelas dan tim perawat juga menekankan stabilitas dan kinerja yang efisien serta pengendalian operasi yang efektif. Tim keperawatan dalam budaya organisasi hierarki mendifinisikan sukses atas dasar efisiensi kerja produktifitas biaya layanan yang murah prosedur pelayanan yang nyaman.

\section{Standar Asuban Keperawatan}

Hasil penelitian menunjukkan bahwa dari 85 responden hampir seluruhnya Standar Asuhan Keperawatan Baik sebanyak 66 responden (77,6 \%). Keperawatan adalah standar praktek keperawatan profesional mengacu pada standar asuhan keperawatan dan standar kinerja profesional perawat. Mutu dari perspektif pasien berpatokan pada dimensi mutu yang terdiri dari: daya tanggap (Responsiveness), Empati (Emphaty), (Courtesy), dan (Sincerity). Standar asuhan keperawatan meliputi lima komponen penting yaitu, Pengkajian Keperawatan, Diagnosis Keperawatan, Perencanaan (Intervensi), Pelaksanaan (Implementasi) dan Evaluasi. Pelaksanaan standar asuhan keperawatan yang baik sangat berhubungan dengan hasil kinerja seorang perawat dan akan menghasilkan mutu asuhan keperawatan yang berkualitas baik (Muhith, 2017). Keberhasilan suatu asuhan keperawatan kepada pasien sangat ditentukan oleh pemilihan metode pemberian asuhan keperawatan professional.Pemilihan sistem pemberian asuhan keperawatan yang tepat untuk setiap unit atau organisasi tergantung pada keterampilan dan keahlian staf, tersedianya tenaga professional, sumber ekonomi dari organisasi, ketajaman dari pasien dan kekompleksan dari tugas yang akan ditanggulangi (Adam 2013).

Hal ini dibuktikan dari pelaksanaan Standar Asuhan Keperawatan di RSI Sakinah Mojokerto selalu dilaksanakan pengkajian: perawat melakukan pengumpulan data tentang status kesehatan pasien secara sistematis menyeluruh, akurat, singkat dan berkesinambungan, Diagnosa Keperawatan: perawat menganalisis data pengkajian untuk merumuskan masalah diagnosis keperawaan, Perencanaan : perawat membuat rencana tindakan keperawatan untuk mengatasi masalah kesehatan dan meningkatkan kesehatan pasien, Impementasi: perawat mengimpementasikan tindakan yang telah diidentifikasi dalam rangka rencana tindakan keperawatan, Evauasi: perawat mengevauasi perkembangan kesehatan 
pasien terhadap tindakan dalam mencapai tujuan sesuai dengan rencana yang ditetapkan dan merevisi data dasar dan perencanaan.

\section{Standar Kinerja Profesional Perawat}

Berdasarkan hasil menunjukkan bahwa dari 85 responden hampir seluruhnya Standar Kinerja Profesional Tinggi, yaitu sebanyak 66 responden (77,6 \%). Pelaksanaan standar kinerja profesional perawat sangat berhubungan dengan hasil kinerja seorang perawat, jika pelaksanaan standar kinerja profesional perawat baik maka akan menghasilkan mutu asuhan keperawatan yang berkualitas baik (Muhith, 2017). Robbins mendefinisikan kinerja sebagai fungsi interaksi antara kemampuan (Ability), motivasi (Motivation) dan kesempatan (oppurtunity). Kinerja perawat diuraikan dalam pemberian asuhan keperawatan melalui proses pengkajian, diagnosa, perencanaan, intervensi, dan evaluasi. Salah satu metode dalam menilai kinerja perawat yaitu dengan melihat standar asuhan keperawatan. Standar Asuhan Keperawatan adalah suatu pernyataan yang menguraikan kualitas yang diinginkan terkait dengan pelayanan keperawatan terhadap klien (Nastiti, 2017). Standar Kinerja Profesional Perawat di Ruang Rawat Inap RSI Sakinah Mojokerto menunjukkan hampir seluruhnya Tinggi. Hal ini dikarenakan perawat di RSI Sakinah terhadap semua pasien memberikan pelayanan yang baik dan selalu bekerja sama dengan tim kesehatan lainnya serta keluarga pasien untuk menyelesaikan masalah pasien tersebut yang dilakukan dengan memberikan pelayanan yang bersifat Caring,Colaboration, Emphaty, Response, Courtesy, dan Sincerity.Salahsatu upaya RSI Sakinah Mojokerto untuk selalu memperahankan hal tersebut adalah dengan melakukan sosialisasi SOP selalu melakukan evaluasi berkala terhadap tindakan-tindakan yang sudah dilakukan oleh perawat.

Hubungan Budaya Organisasi Dengan Mutu Asuban Keperawatan (Standar Asuban Keperawatan)

Berdasarkan tabulasi silang diatas menunjukkan bahwa hampir setengahnya Budaya Organisasi yang dianut adalah Hierarki dengan Standar Asuhan Keperawatan Baik sebanyak 25 responden (29,4\%). Melalui hasil statistik uji Spearman Rank panda taraf sig $(0,05)$ diperoleh hasil korelasi bahwa nilai korelasi $0,018(<0,05)$ artinya ada hubungan Budaya Organisasi dengan Standar Asuhan Keperawatan di Ruang Rawat Inap RSI Sakinah Mojokerto.

Pelayanan asuhan keperawatan sebagai bagian integral pelayanan kesehatan mempunyai kontribusi yang sangat besar dalam menentukan kualitas pelayanan di rumah sakit. Sehingga setiap rumah sakit 
harus meningkatkan kualitas pelayanan keperawatan. Mutu kualitas pelayanan dipengaruhi faktor budaya organisasi (Winasih dkk, 2015). Perawat dalam melaksanakan asuhan keperawatan harus sesuai dengan standar asuhan keperawatan yang ada. Standar asuhan keperawatan adalah uraian pernyataan tingkat kinerja yang diinginkan. Tujuan dan manfaat standar asuhan keperawatan pada dasarnya mengukur kualitas asuhan kinerja perawat dan efektifitas manajemen organisasi (Alessandra 2018).Pembentukan budaya organisasi melalui proses penerapan Metode Asuhan Keparawatan Profesional dapat menyeragamkan dan mensosialisasikan nilai-nilai suatu budaya organisasi kepada perawat(Adam, 2013).

Dominasi budaya hierarki di dalam Ruang Rawat Inap RSI Sakinah Mojokerto mengartikan institusi sebagai tempat yang sangat terkontrol dan terstruktur, melaksanakan tugas kerjanya berdasarkan pada prosedur formal, membuat keputusan secara strategis bagi rumah sakit. Dalam hal ini memberikan gambaran yang jelas bagi pimpinan dan staf untuk melakukan perubahan dan menetapkan langkahlangkah strategis dan prioritas untuk membangun budaya organisasi yang kuat serta meningkatkan keterampilan, kecepatan, kemudahan dan ketepatan dalam melakukan tindakan praktek keperawatan. Budaya yang kuat memiliki pengaruh yang bermakna pada sikap dan kinerja serta dengan adanya budaya organisasi akan menjadi lebih mudah untuk lebih mengarahkan dan memfokuskan dalam meningkatkan mutu asuhan keperawatan.

Hubungan Budaya Organisasi Dengan Mutu Asuban Keperawatan (Standar Kinerja Profesional Perawat)

Berdasarkan tabulasi silang diatas menunjukkan bahwa hampir setengahnya Budaya organisasi yang dianut adalah Hierarki dengan Standar Kinerja Profesional Perawat Tinggi sebanyak 25 responden (29,4\%). Melalui hasil statistik uji Spearman Rank pada taraf sig $(0,05)$ diperoleh hasil korelasi bahwa nilai korelasi $0,018(>0,05)$ artinya ada hubungan Budaya Organisasi dengan Standar Kinerja Profesional Perawat di Ruang Rawat Inap RSI Sakinah Mojokerto. Budaya Organisasi dapat memiliki pengaruh yang bermakna pada sikap dan kinerja karyawannya, ketika budaya organisasi yang dimiliki sebuah perusahaan tersebut kuat(Iranita 2013). Keterlibatan yang tinggi dari perawat pelaksana dalam melakukan kerjasama dalam tim di organisasi akan berdampak pada peningkatan kinerja perawat pelaksana. Pembentukan budaya organisasi melalui proses seleksi dapat menyeragamkan dan mensosialisasikan nilai nilai suatu organisasi kepada perawat pelaksana. Perawat akan memiliki motivasi 
untuk berkarya secara maksimal sesuai dengan apa yang diharapkan organisasi (Iqbal dkk, 2017).

Berdasarkan hasil penelitian yang dilakukan kepada perawat di Ruang Rawat Inap RSI Sakinah Mojokerto dapat dilihat bahwa perawat terhadap semua pasien memberikan pelayanan yang baik, cepat dan tepat dengan pelayanan yang bersifat Caring,Colaboration, Emphaty, Response, Courtesy, dan Sincerity. Dimana Tim keperawatan dalam budaya organisasi hierarki mendifinisikan sukses atas dasar efisiensi kerja produktifitas biaya layanan yang murah prosedur pelayanan yang nyaman serta menekankan stabilitas dan kinerja yang efisien. Rumah Sakit yang memiliki budaya organisasi, akan lebih terkontrol, terstruktur jelas dan menekankan stabilitas dan bertanggung jawab terhadap pekerjaan, salah satunya dalam memberikan asuhan keperawatan yang sesuai dengan standar kinerja profesional perawat agar tercapai tujuan yang telah ditetapkan serta kinerja yang efisien.

\section{KESIMPULAN}

Hampir setengahnya Budaya Organisasi yang dianut di Ruang Rawat Inap di RSI Sakinah Mojokerto adalah budaya Hierarki. Hampir seluruhnya Mutu Asuhan Keperawatan menunjukkan bahwa (Standar Asuhan Keperawatan) baik dan (Standar Kinerja Profesional) tinggi. Ada hubungan Budaya Organisasi dengan Mutu Asuhan Keperawatan (Standar Asuhan
Keperawatan dan Standar Kinerja Profesional Perawat) di Ruang Rawat Inap di RSI Sakinah Mojokerto.

\section{SARAN}

Sebagai bahan untuk kajian konseptual ilmu keperawatan tentang ilmu dasar Budaya Organisasi untuk mengetahui berapa banyak kultur budaya organisasi dalam suatu organisasi maupun suatu instansi. Menjadikan bahan untuk meningkatkan upaya pengembangan keterampilan kepada perawat dalam pemberian asuhan keperawatan seperti, mengadakan pelatihan secara berkesinambungan sehingga nantinya perawat mampu memberikan pelayanan dengan terampil dalam asuhan keperawatan.

\section{REFERENSI}

Adam, A. Rino.2013. "Pengembangan Budaya Organisasi Keperawatan Untuk Meningkatkan Kinerja Dan Kepuasan Perawat Dalam Penerapan Metode Asuban Keperawatan Profesional'. Disertasi Doktor tidak dipublikasikan Fakultas Kesehatan Masyarakat Universitas Airlangga Surabaya

Dahlan, M. Sopiyudin.2010. Besar Sampel Dan Cara Pengambilan Sampel Dalam Penelitian Kedokteran Dan Kesehatan. Jakarta: Salemba Medika

Abdul Muhith., Mukhammad Himawan Saputra., Fenty. (2017). Gambaran Tingkat Turnover Perawat, Motivasi, Dan Kinerja Perawat Di Rumah Sakit Islam Hasanah Mojokerto. Prosiding Seminar Nasional Hasil Penelitian Dan 
Pengabdian Masyarakat Seri Ke-1 Tahun 2017.

Fauzan, Oceano Muhammad., \& Fathiyah. (2017). Pengaruh Budaya Organisasi, Gaya Kepemimpinan Dan Pengawas Terhadap Motivasi Serta Dampaknya Terbadap Kinerja Pegawai Dinas Pekerjaan Umum (Pu) Kabupaten Batang Hari Jambi. JMAS Vol.2 No.2.

Hardika, Revani. (2017). Pengembangan Model Budaya Organisasi Terbadap Kepuasan Kerja Dan Kinerja Perawat Di Rumah Sakit Islam Banjarmasin. Dinamika Kesehatan, Vol.8 No.1 (Juli 2017)

Iqbal , Muhammad.,\& Agritubella Meri Syafrisar. (2016). Hubungan Budaya Organisasi dengan Kinerja Perawat Pelaksana Di Ruang Rawat Inap RS PMC. Jurnal Endurance 2(3) Oktober (2017) (285-29)

Kalsum, Umi., La Ode Ali Imran Ahmad., Wa Ode Sitti Nurzalmariah Andisiri. (2017). Pengaruh Budaya Organisasi Terbadap Kinerja Perawat Pelaksana Di Ruang Rawat Inap Rumah Sakit Umum Babteramas Provinsi Sulawesi Tenggara Tabun 2016. Jurnal Jurnal Ilmiah Mahasiswa Kesehatan Masyarakat Vol. 2/No.6/ Mei 2017; ISSN 250-731X.

Muhith, Abdul,. M. Himawan Saputra, Nursalam.(2013). Bauran Pemasaran Dengan Bed Occupancy Ratio (BOR)(Marketing Mix by Bed Occupancy Ratio (BOR))

Muhith, Abdul. (2017). Pengembangan Model Mutu Asuban Keperawatan dan MAKP. Yogyakarta : Cv Threeprenuer

Muhith, Abdul., \& Nursalam. Mutu Asuban Keperawatan Berdasarkan Analisis Kinerja Perawat Dan Kepuasan Perawat Dan Pasien. Jurnal Ners Vo.7 No. 1 (April 2012):47-55

Muhith. A , dkk. (2011). Buku Ajar Metode Penelitian Kesehatan : Konsep Pembuatan
Karya Tulis Dan Thesis Untuk Mahasisawa Keperawatan. Yogyakarta : Nuha Medika

Muhith, A. (2017). Pengembangan model mutu asuhan keperawatan dan MAKP. Yogyakarta: cv. Enterpreuner.

Muhith, A. (2018). Aplikasi Komunikasi terapeutik Nursing \& Health Yogyakarta: Andi.

Muhith, A., dkk (2019). Healthcare Quality and Justice Quality: Its Effects on Patient Satisfaction in the National Health Insurance Era (2019/3/24), published KnE Social Sciences, 549567-549-567

Muhith, A., dkk (2016).. Nursing Service Quality Model Based on Nursing Performance and Patient Satisfaction Analysis in Gresik District Hospital journal of health medicine and nursing, 23, ISSN 2422-8419

Muhith, A., dkk (2017). nursing service quality model based on the nursing performance, nurse and patient satisfaction. Jurnal Ners Vol.7 No.1. Fakultas Keperawatan Universiatas Airlangga Surabaya.

Nastiti, Ayu Dewi .(2017). Pelatihan Caring Dengan Model Partisipatif Untuk Peningkatan Kinerja Perawat Dan Mutu Layanan Keperawatan. Jurnal Penelitian Kesehatan Suara Forikes .Volume VIII Nomor 4, Oktober 2017 ISSN 2086-3098 (p) ISSN 2502-7778 (e)

Pratiwi, Ana. (2016). Implementasi Sistem Manajemen Mutu Pelayanan Keperawatan Melalui Kepemimpinan Mutu Kepala Ruangan.Jurnal Ners Vol. 11 No.1 April 2016: 1-6

Winasih. Rini,. Nursalam., Ninuk Dian K. 2015. Budaya Organisasi Dan Quality Of Nursing Work Life Terhadap Kinerja Dan Kepuasan Kerja Perawat Di Rsud Dr. Soetomo Surabaya. Jurnal Ners Vol. 10 No. 2 Oktober 2015: 332-342. 